Original Paper

\title{
多分散ナノ粒子測定用のラグ付フィボナッチ数列型 指数サンプリング相関器の開発
}

\author{
Development of an Exponential Sampling Correlator with \\ Lagged Fibonacci Series for Polydisperse Nanoparticles
}

\author{
山口 哲司 ${ }^{a, b}$, 河原林 成行 ${ }^{a}$, 奥山 喜久夫 ${ }^{b}$
}

Tetsuji Yamaguchi, Shigeyuki Kawarabayashi, Kikuo Okuyama

\begin{abstract}
Received 10 July 2007 ; Accepted 18 October 2007
Correlator of a photon correlation spectroscopy (PCS) apparatus for measuring nanoparticles with a polydisperse distribution has been developed with unique data sampling methods. In the present exponential sampling correlator, the sampling times are increased by various geometrical ratios, each of which relates the integral multiples of minimum sampling time to the individual channels. The geometrical progressions are able to transform the data into the lagged Fibonacci series. Simulation results show that the newly developed correlator has an improved performance over the conventional exponential sampling correlator because no rounding errors occur in the processing of the data.
\end{abstract}

Keywords : Photon correlation spectroscopy, Exponential sampling correlator, Geometrical ratio, Lagged Fibonacci series, Rounding error, Bias noise

\section{1. 緒言}

近年，さまざまな分野でナノ粒子に関する研究が盛 んにおこなわれている。これに合わせて，対象となる ナノ粒子を計測評価する技術の必要性が増している。

筆者らは, ナノ粒子の計測に有力な計測手法の一つ である光子相関法 (Photon Correlation Spectroscopy, 以下, PCS と言う)" ${ }^{1)}$ を用いた装置の開発を 進めている ${ }^{2)}$ 。ナノ粒子の粒子径分布を測定するため には，10nm 以下の粒子径を持つナノ粒子（以下， シ ングルナノ粒子と言う）からミクロン粒子の測定用に 最適化されたPCS 装置を開発することが必要であ

\footnotetext{
a 株式会社堀場製作所

(テ601-8510 京都府京都市南区吉祥院宮の東町 2)

TEL 075-313-8121

HORIBA, Ltd.

(2 Miyanohigashi, Kisshoin, Minami-ku, Kyoto 601-8510, Japan)

b 広島大学大学院 工学研究科 物質化学システム専攻

(テ739-8527 広島県東広島市鏡山 1-4-1) TEL 0824-24-7716

Department of Chemical Engineering, Graduate School of Engineering, Hiroshima University

(1-4-1, Kagamiyama, Higashi-hiroshima, Hiroshima 7398527, Japan)
}

る。そこで, 筆者らは, これまでブラウン運動するシ ングルナノ粒子からの散乱光パルスを等間隔で確実に 捉えるために，線形サンプリングのユニタウマルチ ビットコリレータ (Uni-Tau Multi-Bit Correlator 以下，UMC と言う) ${ }^{3)}$ を製作し，単分散粒子に対す る静的な場における基本性能の評価を行ってきた。一 方, 近年, 自動車, 環境, IT, バイオなど種々分野 で, 微粒子計測の需要が高まり, 単一の粒子径ではな い種々の粒子径の粒子が混合された静的場や, 時間と ともに粒子径が変化する動的場における測定の要求が 高まっている。すなわち，2山，もしくは，3山など 複数のピークをもった多分散粒子径分布を示すことが 多い。従来, このような多分散系を一度に測定するた めに，指数サンプリングコリレータ (ExponentialTau Multi-Bit Correlator, 以下, EMC と言う) ${ }^{4)}$ が 広く用いられている。従来の EMC では，できるだけ 少ないチャネル数で, 広い範囲の自己相関関数 (Auto Correlation Function, 以下, ACF と言う) を得る ために，指数的にサンプリング間隔を長くして測定す る。このため, ACF の横軸である遅れ時間の速い時 間帯では, 解析時にデータの点数が不足して正確な 
分布が得られないという問題を引き起こす。また， 各チャネル間のバイアスノイズの問題で測定精度に 影響されることが報告されている5)。これに対して， 著者らは，UMCにはバイアスノイズがなく，EMC と 比較して優位性があることを証明し提言した ${ }^{6)}$ 。今 回，このUMC の精度を保ったままで，多分散系に対 応する広い時間範囲の情報を得ることが可能である ラグ付フィボナッチ数列型指数サンプリングコリレー 夕 (Lagged-Fibonacci-Series Exponential-Tau Multi-Bit Correlator, 以下, LFS-EMC と言う) を設計した。

本論文では, LFS-EMC の基本方式と性能につい て, シミュレーション結果と合わせて報告する。

\section{2. 測定原理と装置設計の課題}

\section{1 光子相関法}

PCSに関しては，成書に詳述されており良く知ら れているので1)，ここでは簡単に説明する。PCSで は, 波長 $\lambda_{0}$ のレーザ光をブラウン運動している粒子 に照射すると，それぞれの粒子固有の動きや振動に より, 散乱光が位相差のために摇らぎを生じる。散 乱光の強度は光子の数として検出されるので, ある 時刻 $t$ における粒子からの散乱光子数 $n(t)$ 之, 時間 $\tau$ 後の散乱光子数 $n(t+\tau)$ との ACF をとる。実際に は, 測定場には種々の粒子が存在するので, 統計的 に集合平均をとると, ACF は次式のように与えられ る。

$$
\begin{aligned}
& G_{2}(\tau)=\frac{\langle n(t) \cdot n(t+\tau)\rangle}{\langle n(t)\rangle^{2}} \\
& G_{2}(\tau)=1+\left|G_{1}(\tau)\right|^{2} \\
& G_{1}(\tau)=\mathrm{e}^{-\Gamma \tau} \\
& \Gamma=\boldsymbol{q}^{2} D \\
& \boldsymbol{q}=\frac{4 \pi n_{0}}{\lambda_{0} \cdot \sin (\theta / 2)} \\
& D=\frac{K T}{3 \pi \eta_{0} d}
\end{aligned}
$$

ここで, Eq. (1) より, 測定装置などの応答関数を 含んだ二次の ACF である $G_{2}(\tau)$ が観測され, 粒子の 動きそのものの一次の ACF である $G_{1}(\tau)$ とは, Eq. (2) の関係で表せる。一般的に $G_{1}(\tau)$ は, Eq. (3)の ような特性减衰時間 $1 / \Gamma$ を指数とする指数関数とな るので, これを測定結果から求めると, Eq. (4) と Eq. (5) の散乱ベクトル $\boldsymbol{q}$ を用いて, 粒子のブラウン 拡散係数 $D$ が算出でき, Eq. (6) の Stokes-Einstein

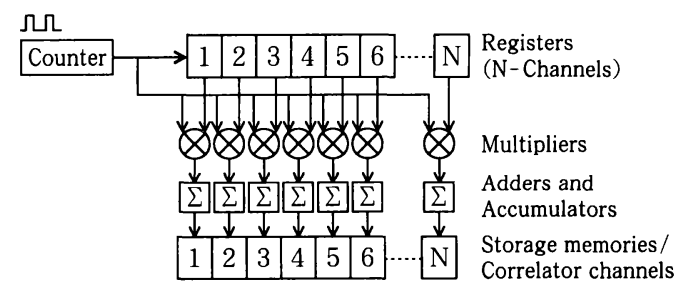

Fig. 1 Block diagram of the UMC

式からナノ粒子の粒子径 $d$ が算出できることになる。

\section{2 コリレータ}

UMC のブロック図を Fig. 1 に示した。各チャネル のレジスタ内の計数值は最新の観測計数值と乗算器 (Multiplier) で掛け合わされ，その結果と累算器 (Accumulator) 内の累積値を加算器 (Adder) で加算 し，その結果をストレージメモリ (Storage Memory) に保存した。この各メモリの数值が ACF の各チャネ ルの数值となる。EMCのコリレータのブロック図を

Fig. 2 に示した。

UMC によるACF を, Eq. (7a) で示した。UMCで は, 隣のチャネルとの時間間隔が等間隔のサンプリン グ間隔を持つ。また，EMCの場合は，Eq. (7b) とな り, 隣のチャネルとの時間間隔が, 公比 $r$ の等比数列 的に増加するサンプリング間隔を持つ。

$$
\begin{aligned}
G\left(t_{\mathrm{i}}\right)= & \frac{N \cdot \sum n(0) \cdot n\left(t_{\mathrm{i}}\right)}{\left\{\sum n(0)\right\}^{2}} \\
& t_{\mathrm{i}}=i \cdot \tau(i=1,2,3, \ldots) \\
G\left(t_{\mathrm{i}}\right)= & \frac{N \cdot \sum n(0) \cdot n\left(t_{\mathrm{i}}\right)}{\left\{\sum n(0)\right\}^{2}} \\
& t_{\mathrm{i}}=r^{\mathrm{i}-1} \cdot \tau(i=1,2,3, \ldots)
\end{aligned}
$$

\section{3 従来コリレータの課題}

市販装置で良く使われている EMC は，一般に 7 桁 以上の広いレンジを測定可能粒子径対象としており， サンプリング間隔をチャネル後段へ行くほど等比数列 的に長くして, 少ないチャネル数で広い粒子径範囲の

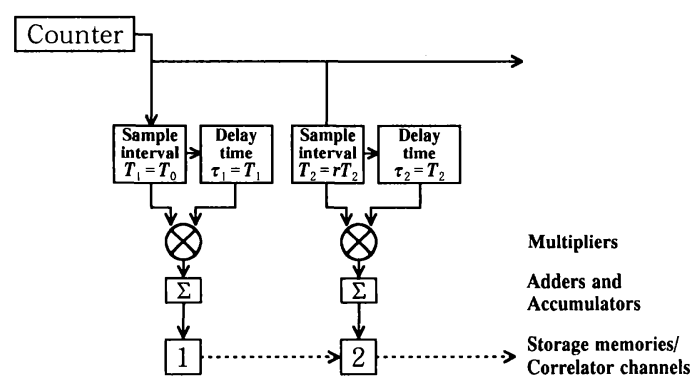

Fig. 2 Block diagram of the EMC 
観測を可能としている。しかし, 散乱光パルスをカウ ントするタイミングと $\mathrm{ACF}$ 演算の遅延時間のタイミ ングが必ずしも一致せず，各チャネルにおいて，重 複, あるいは, 欠落し, これに伴い ACF のベースラ インが不安定となる等の問題が指摘されている ${ }^{5)}$ 。ま た, 公比 $r$ は, 実際に, コリレータのクロックやデー 夕点数, チャネル数の関係から, $1<r<2$ が最適な値 となる。これは前述のとおり, 計算上, 各チャネルが 示す ACF の遅れ時間 $\tau$ と各チャネルが光子パルスを カウントするサンプリング時間の区切りが一致しない ことに起因する。このような問題を解決するために, 全チャネルで同一のサンプリング間隔（ユニタウ）で 動作し, マルチビットで測定場の情報の重複や久落

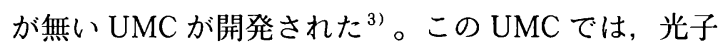
パルスをカウントするサンプリング間隔が ACF の遅 延時間と一致しているために実現できる。この UMC を使うことにより, シングルナノ粒子のブラウン運 動を高速サンプリングで正確に捉え, 高速演算処理 により瞬時の測定が可能となる。しかし， 7 桁以上 の広いレンジを測定可能粒子径対象とした場合に, 同じ精度で演算するには少なくとも 6 桁以上のチャネ ル数を必要とし, チャネル数が不足した場合には, $\mathrm{ACF}$ の後段の演算が打ち切られてしまう問題があっ た。

\section{3. 相関器設計の最適化}

3. 1 ラグ付フィボナッチ数列型指数サンプリング法 7 桁以上の広いレンジを持つ多分散粒子径分布を測 定対象とし, 従来の指数サンプリング法を用いるが, 情報量が久落することなく，チャネル間のバイアスノ イズもなく測定を可能とする解決策の一つにLFSEMC を考案した。この LFS-EMC は, 連続する好適 な公比 $r$ をもつ等比数列となり, 広い測定レンジを全 チャネルで測定できるようにカバーするような公比 $r$ が設定できる。

従来法では, サンプリング間隔が, 直前のサンプリ ング間隔のみで決まるため, 好適な公比 $r$ が決まり,

Eq. (9a) でサンプリングレート $f_{\mathrm{n}}$ が決まる。結果的 に生成された数列によるサンプリング時間が, ACF の遅延時間のタイミングに合わない場合には, サンプ リング間隔を調整して比較的条件に近いサンプリング 間隔で妥協することになった。

しかし, LFS-EMC の最大の特徴は, UMC のサン プリング間隔 $T_{0}$ 単位の整数倍で得られるサンプリン グ間隔 $T_{\mathrm{n}}$ を決めるサンプリングレート $f_{\mathrm{n}}$ が, 要素 $f_{\mathrm{n}-1}, f_{\mathrm{n}-2}, f_{\mathrm{n}-3}, \cdots, f_{1}$ などの適当な組み合わせ で，すなわち， $f_{\mathrm{n}}$ を，その要素である $f_{\mathrm{n}-1}, f_{\mathrm{n}-2}$, $f_{\mathrm{n}-3}, \cdots, f_{1}$ の加算で構成できるという性質を利用 するところである。つまり, 公比 $r$ の整数倍の等比数 列が, たとえば, 有名なフィボナッチ数列のような整 数列と置き換えられることになる。具体的には, 公比 $r$ の等比数列を用いる指数サンプリングでは, $n$ チャ ネル目のサンプリング間隔 $T_{\mathrm{n}}$ は, Eq. (8a) と表せ る。ここで $T_{0}$ が最小サンプリング間隔をなす基本ク ロックとすると, デジタル相関器のサンプリング間隔 や遅延時間は, 基本クロックを単位として, その個数 で決まり， $T_{\mathrm{n}}$ は, Eq. $(8 \mathrm{~b})$ で表される。さらに, $f_{\mathrm{n}}$ は $n$ チャネル目の $T_{0}$ の個数となり, Eq. (9a) で表さ れる。従来法では, $T_{\mathrm{n}}, T_{\mathrm{n}-1}, \cdots は, r$ が $1<r<2$ であるならば実数であり, $r^{\mathrm{n}}$ も実数となることから $f_{\mathrm{n}}$ も実数である。そこで, $f_{\mathrm{n}}$ を整数化して整数值の サンプリングレート $\left[f_{\mathrm{n}}\right]$ を適用していた。

つまり， $\varepsilon_{\mathrm{n}}$ を $n$ チャネルにおける整数化による䛊 差とすると, $f_{\mathrm{n}}$ は Eq. (9b) で表せることから, サン プリング時間が本来值より $r \varepsilon_{\mathrm{n}-1} T_{0}$ だけ増減するこ とになり，その間にパルスがきたとき，重複してカウ ントするか, 見逃すかという不都合が生じ, 精度が下 がる原因となっていた。

$$
\begin{aligned}
& T_{\mathrm{n}}=r \cdot T_{\mathrm{n}-1}=r^{\mathrm{n}} \cdot T_{0} \\
& T_{\mathrm{n}}=f_{\mathrm{n}} \cdot T_{0} \\
& f_{\mathrm{n}}=r \cdot f_{\mathrm{n}-1}=r^{\mathrm{n}} \cdot f_{1} \\
& f_{\mathrm{n}}=r \cdot\left(f_{\mathrm{n}-1}+\varepsilon_{\mathrm{n}-1}\right)
\end{aligned}
$$

そこで以下のように，本質的に $f_{\mathrm{n}}$ が整数となり, 整数化処理が不要な等比数列の構成法を考案した。

等比数列は, その要素 $f_{\mathrm{n}-1}, f_{\mathrm{n}-2}, f_{\mathrm{n}-3}, \cdots, f_{1}$ の 適当な組み合わせの漸化式で構成できる。漸化式を何 項間から作るか, あるいは, 何項を使うかによってさ まざまな公比 $r$ を作ることが可能となる。そのうちの 数例を証明すると, 3 項間の漸化式の場合は, Eq. (10a) から Eq. (10e) のように, $f_{\mathrm{n}}$ は $f_{\mathrm{n}-1}, f_{\mathrm{n}-2}$, $\cdots, f_{1}$ のうち $f_{\mathrm{n}-1}$ と他の 1 要素を用いて,

$$
\begin{aligned}
f_{\mathrm{n}} & =r \cdot f_{\mathrm{n}-1}=f_{\mathrm{n}-1}+(r-1) \cdot f_{\mathrm{n}-1} \\
& =f_{\mathrm{n}-1}+f_{\mathrm{n}-2}+\{r \cdot(r-1)-1\} \cdot f_{\mathrm{n}-2} \\
& =f_{\mathrm{n}-1}+f_{\mathrm{n}-3}+\left\{r^{2} \cdot(r-1)-1\right\} \cdot f_{\mathrm{n}-3} \\
& =f_{\mathrm{n}-1}+f_{\mathrm{n}-4}+\left\{r^{3} \cdot(r-1)-1\right\} \cdot f_{\mathrm{n}-4} \\
& =\cdots \\
& =f_{\mathrm{n}-1}+f_{1}+\left\{r^{\mathrm{n}-2} \cdot(r-1)-1\right\} \cdot f_{1}
\end{aligned}
$$

と表すことができる。 
同様に, $f_{\mathrm{n}-2}$ とそれ以前の他の 1 要素 $f_{\mathrm{n}-3}, f_{\mathrm{n}-4}$, $\cdots, f_{1}$ を用いた場合には，Eq. (11a) から Eq. (11e) のように,

$$
\begin{aligned}
f_{\mathrm{n}} & =r^{2} \cdot f_{\mathrm{n}-2}=f_{\mathrm{n}-2}+\left(r^{2}-1\right) \cdot f_{\mathrm{n}-2} \\
& =f_{\mathrm{n}-2}+f_{\mathrm{n}-3}+\left\{r \cdot\left(r^{2}-1\right)-1\right\} \cdot f_{\mathrm{n}-3} \\
& =f_{\mathrm{n}-2}+f_{\mathrm{n}-4}+\left\{r^{2} \cdot\left(r^{2}-1\right)-1\right\} \cdot f_{\mathrm{n}-4} \\
& =f_{\mathrm{n}-2}+f_{\mathrm{n}-5}+\left\{r^{3} \cdot\left(r^{2}-1\right)-1\right\} \cdot f_{\mathrm{n}-5} \\
& =\cdots \\
& =f_{\mathrm{n}-2}+f_{1}+\left\{r^{n-3} \cdot\left(r^{2}-1\right)-1\right\} \cdot f_{1}
\end{aligned}
$$

と表すことができる。

以上より，一般的に, $f_{\mathrm{n}}$ を $f_{\mathrm{n}-\mathrm{i}}$ と $f_{\mathrm{n}-\mathrm{j}}$ の 3 項間の 漸化式で表すと， Eq. (12a）から Eq. (12c) のよう に,

$$
\begin{aligned}
& f_{\mathrm{n}}=f_{\mathrm{n}-\mathrm{i}}+f_{\mathrm{n}-\mathrm{j}}+\left\{r^{\mathrm{j}-\mathrm{i}} \cdot\left(r^{\mathrm{i}}-1\right)-1\right\} \cdot f_{\mathrm{n}-\mathrm{j}} \\
& i=1,2, \ldots \\
& j=i+1, i+2, \ldots
\end{aligned}
$$

と表すことができる。

さらに, $f_{\mathrm{n}}$ は, $f_{\mathrm{n}-1}$ と $f_{\mathrm{n}-2}$ と他の 1 要素を用いた 4 項間の漸化式の場合には, Eq. (13a) から Eq. (13e) のように

$$
\begin{aligned}
f_{\mathrm{n}}= & r \cdot f_{\mathrm{n}-1}=f_{\mathrm{n}-1}+(r-1) \cdot f_{\mathrm{n}-1} \\
= & f_{\mathrm{n}-1}+f_{\mathrm{n}-2}+\{r \cdot(r-1)-1\} \cdot f_{\mathrm{n}-2} \\
= & f_{\mathrm{n}-1}+f_{\mathrm{n}-2}+f_{\mathrm{n}-3} \\
& +[r \cdot\{r \cdot(r-1)-1\}-1] \cdot f_{\mathrm{n}-3} \\
= & f_{\mathrm{n}-1}+f_{\mathrm{n}-2}+f_{\mathrm{n}-4} \\
& +\left[r^{2} \cdot\{r \cdot(r-1)-1\}-1\right] \cdot f_{\mathrm{n}-4} \\
= & \cdots \\
= & f_{\mathrm{n}-1}+f_{\mathrm{n}-2}+f_{1} \\
& +\left[r^{\mathrm{n}-3} \cdot\{r \cdot(r-1)-1\}-1\right] \cdot f_{1}
\end{aligned}
$$

と表すことができる。

証明は省略するが, 同様にして, 多項間の漸化式 が，すべて $f_{\mathrm{n}}$ の漸化式で表されることが分かる。

このように 3 項間の場合は, Eq. (12a) の最後の項 を $R(r)$ とすると, $R(r)=0$ となる $r$ に収束する。こ のことは, $f_{\mathrm{n}-\mathrm{i}}$ と $f_{\mathrm{n}-\mathrm{j}}$ の加算により $f_{\mathrm{n}}$ が, Eq. (14) で構成できることを示している。

$$
f_{\mathrm{n}}=f_{\mathrm{n}-\mathrm{i}}+f_{\mathrm{n}-\mathrm{j}}
$$

また，この関係の一般式を， $k<n-1$ である $k$ と， $l<n-2$ である $l$ を用いて Eq. (15e) とし， $u, v$ を Eq. (15f) とおくと, Eq. (15g) に帰着する。この算 出は省略するが, $x^{2}+u x+v=0$ の根を $\alpha, \beta$ とする
之, 一般項は, 解析的に求めることができて $\mathrm{Eq}$. （15i）と解くことができる。

$$
\begin{aligned}
& f_{\mathrm{n}-1}=r \cdot f_{\mathrm{n}-2}=r^{2} \cdot f_{\mathrm{n}-3}=r^{3} \cdot f_{\mathrm{n}-4}=\cdots \\
& f_{\mathrm{n}-2}=\frac{1}{r} \cdot f_{\mathrm{n}-1}, f_{\mathrm{n}-3}=\frac{1}{r^{2}} \cdot f_{\mathrm{n}-1}, \cdots \\
& f_{\mathrm{k}}=\frac{1}{r^{\mathrm{n}-1-\mathrm{k}}} \cdot f_{\mathrm{n}-1} \quad k=n-2, n-3, \cdots \\
& f_{l}=\frac{1}{r^{\mathrm{n}-2-l}} \cdot f_{\mathrm{n}-2} \quad l=n-3, n-4, \cdots \\
& f_{\mathrm{n}}=f_{\mathrm{k}}+f_{l}=\frac{1}{r^{\mathrm{n}-1-\mathrm{k}}} \cdot f_{\mathrm{n}-1}+\frac{1}{r^{\mathrm{n}-2-l}} \cdot f_{\mathrm{n}-2} \\
& u=\frac{1}{r^{\mathrm{n}-1-\mathrm{k}}}, v=\frac{1}{r^{\mathrm{n}-2-l}} \text { とおくと } \\
& f_{\mathrm{n}}=u \cdot f_{\mathrm{n}-1}+v \cdot f_{\mathrm{n}-2} \\
& f_{\mathrm{n}}=\frac{\alpha^{\mathrm{n}-1}-\beta^{\mathrm{n}-1}}{\alpha-\beta} \cdot f_{2}+\frac{\alpha \cdot \beta^{\mathrm{n}-1}-\beta \cdot \alpha^{\mathrm{n}-1}}{\alpha-\beta} \cdot f_{1} \\
& u=\alpha+\beta, v=-\alpha \cdot \beta
\end{aligned}
$$

これによって，(1)好適な $r$ が求まれば，(2)Eq. (14) の $i, j$ が求まり, (3)公比 $r$ の整数等比数列が算出さ れ，(4)Eq. (15i) のように初期值 $f_{2}, f_{1}$ によって，一 般項が算出される。これによって, 指数サンプリング の各チャネルの光子数のカウントに重複や欠落を生じ ることがなく, ベースラインの不安定性を生じること のないコリレータのサンプリングシステムが構成でき る。

\section{4. 実験結果と考察}

前述の具体例を以下に示すと, Eq. (10b) の第 3 項 が 0 とすると, Eq. (16a) のように, フィボナッチ数 列となる。このとき, $r=1.618$ を公比とする等比数 列 Eq. (16b) を構成する。

$$
\begin{aligned}
& f_{\mathrm{n}}=f_{\mathrm{n}-1}+f_{\mathrm{n}-2} \\
& f_{\mathrm{n}}=1.618 \cdot f_{\mathrm{n}-1}
\end{aligned}
$$

また, Eq. (10c) の第 3 項が 0 とすると, Eq. (17a) のような数列となる。このとき, $r=1.466$ を公比と する等比数列 Eq. (17b) を構成する。

$$
\begin{aligned}
& f_{\mathrm{n}}=f_{\mathrm{n}-1}+f_{\mathrm{n}-3} \\
& f_{\mathrm{n}}=1.466 \cdot f_{\mathrm{n}-1}
\end{aligned}
$$

また, Eq. (10d) の第 3 項が 0 とすると, Eq. (18a) のような数列となる。このとき, $r=1.380$ を公比と する等比数列 Eq. (18b) を構成する。 


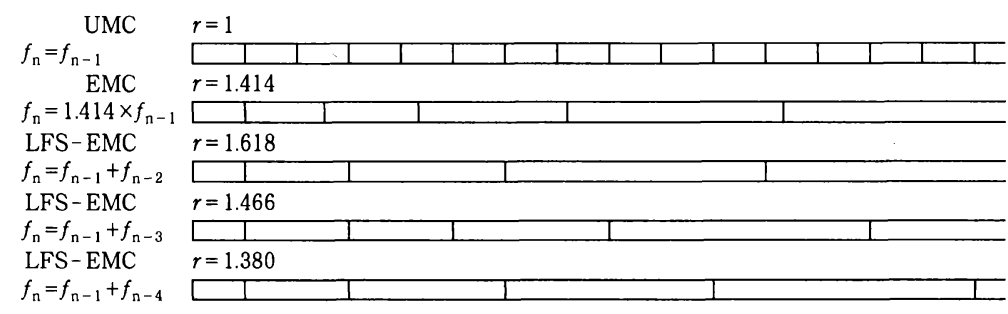

Fig. 3 Channel architecture of the UMC, the EMC and three kinds of the LFS-EMC

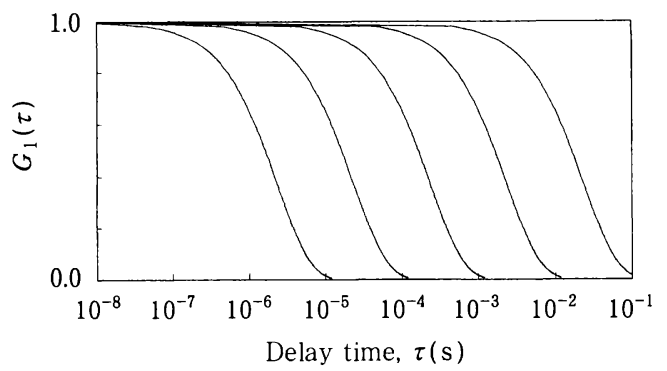

Fig. 4 Calculated ACF from $1 \mathrm{~nm}$ particles to $10 \mu \mathrm{m}$ particles

$$
\begin{aligned}
& f_{\mathrm{n}}=f_{\mathrm{n}-1}+f_{\mathrm{n}-4} \\
& f_{\mathrm{n}}=1.380 \cdot f_{\mathrm{n}-1}
\end{aligned}
$$

Fig. 3 に, UMC, EMC, および, LFS-EMC のサン プリングのタイミングチャートを示した。このチャー トから, UMC は, 基本クロックの倍数でサンプリン グされていくのに対して, EMCは, 基本クロックと 一致しない時間までのサンプリングを行う必要がある こと。そして，LFS-EMC はいずれも EMC と同様の

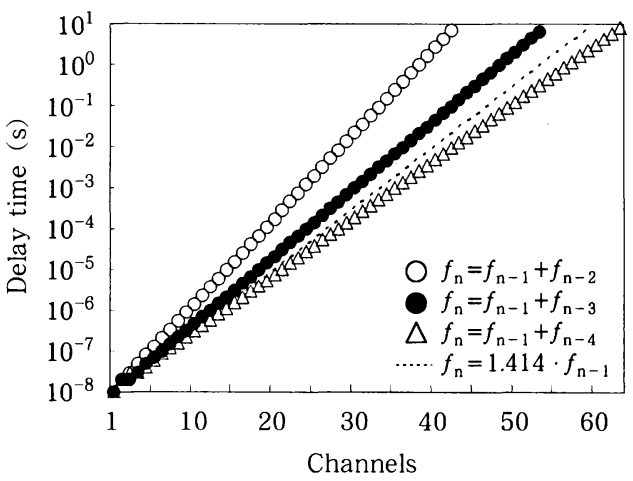

Fig. 5 Relationships between channel and delay time in the EMC and three kinds of the LFS-EMC

整数值でない公比を持つにもかかわらず，基本クロッ クの整数倍のサンプリング時間に一致したタイミング でサンプリングされていることが分かる。

Eq. (3) より粒子径が $1 \mathrm{~nm}, 10 \mathrm{~nm}, 100 \mathrm{~nm}, 1 \mu \mathrm{m}$, $10 \mu \mathrm{m}$ の場合の ACF を計算したものを Fig. 4 に示し た。これらの $\mathrm{ACF}$ から, $1 \mathrm{~nm}$ から $10 \mu \mathrm{m}$ の遅延時間

\begin{tabular}{|c|c|c|c|c|c|}
\hline & EMC & & & LFS-EMC & \\
\hline \multicolumn{6}{|l|}{$\mathrm{CH}$} \\
\hline \multicolumn{3}{|c|}{$f_{\mathrm{n}}=1.414 \times f_{\mathrm{n}-1}$} & $\begin{array}{c}f_{\mathrm{n}}=f_{\mathrm{n}-1}+f_{\mathrm{n}-2} \\
f_{\mathrm{n}}=1.618 \times f_{\mathrm{n}-1}\end{array}$ & $\begin{array}{c}f_{\mathrm{n}}=f_{\mathrm{n}-1}+f_{\mathrm{n}-3} \\
f_{\mathrm{n}}=1.466 \times f_{\mathrm{n}-1}\end{array}$ & $\begin{array}{c}f_{\mathrm{n}}=f_{\mathrm{n}-1}+f_{\mathrm{n}-4} \\
f_{\mathrm{n}}=1.380 \times f_{\mathrm{n}-1}\end{array}$ \\
\hline$n$ & $f_{\mathrm{n}}$ & {$\left[f_{\mathrm{n}}\right]$} & $f_{\mathrm{n}}$ & $f_{\mathrm{n}}$ & $f_{\mathrm{n}}$ \\
\hline 1 & 1.000 & 1 & 1 & 1 & 1 \\
\hline 2 & 1.414 & 1 & 2 & 2 & 2 \\
\hline 3 & 2.000 & 2 & 3 & 2 & 3 \\
\hline 4 & 2.828 & 3 & 5 & 3 & 4 \\
\hline 5 & 4.000 & 4 & 8 & 5 & 5 \\
\hline 6 & 5.657 & 6 & 13 & 7 & 7 \\
\hline 7 & 8.000 & 8 & 21 & 10 & 10 \\
\hline 8 & 11.314 & 11 & 34 & 15 & 14 \\
\hline 9 & 16.000 & 16 & 55 & 22 & 19 \\
\hline 10 & 22.627 & 23 & 89 & 32 & 26 \\
\hline 11 & 32.000 & 32 & 144 & 47 & 36 \\
\hline
\end{tabular}

Table 1 Sampling rate on each channel of EMC and LFS-EMC 
は7桁必要であり, 10ns から $100 \mathrm{~ms}$ の広い領域で測 定する必要があることが分かる。Fig. 5 に, 公比 $r=$ 1.414 をもつ EMC の場合と, Eq. (16a), Eq. (17a), Eq. (18a) を使った LFS-EMC の場合のチャネル数 と遅れ時間の関係を示した。得られた ACF から粒子 径分布を演算するために必要なチャネル数を考えて, いずれも 64 チャネル以下で, 10ns から 100ms まで が測定可能で, 少ないチャネル数で広い範囲の測定が できることが確認できた。

Table 1 に, チャネル番号 $n$ とサンプリングレート $f_{\mathrm{n}}$ との関係を示した。EMCで通常良く使われてい る公比 $r=1.414$ を持った等比数列と, LFS-EMC を 使って, それぞれの公比が $r=1.618,1.465,1.380$ で ある三つの等比数列をもつサンプリングレートを比較 して示した。EMC の場合は, 公比 $r=1.414$ であるこ とからサンプリングレート $f_{\mathrm{n}}$ はすべて実数となる。 この実数は整数化処理されて $\left[f_{\mathrm{n}}\right]$ として扱われる。
しかし， LFS-EMC の場合は, 等比数列であるとと もに，それぞれが漸化式でも書き換えられる。この 時, サンプリングレートがすべて整数值となっている ことが分かる。このことから LFS-EMC の場合は, 本質的に，サンプリングレートが基本サンプリング間 隔の整数倍であり, カウント数と演算に用いるパルス 数に重複や欠落がなく, 整合良く $\mathrm{ACF}$ が求められる ので測定精度が向上することが証明された。

\section{5. 結言}

本研究で, 多分散粒子径分布測定をする上で最適な LFS-EMC サンプリング方法を考案し検証した結果, 実際にカウントするサンプリング時間と, ACF 演算 の遅れ時間とが一致しており, 丸め䛊差による光子 パルス数の重複や欠落が生じないことが, シミュレー ションを通して明らかになった。

$\begin{array}{ll}D & : \text { diffusion coefficient } \\ d & : \text { diameter of particle } \\ f & : \text { sampling rate } \\ G_{1}(\tau) & : \text { first order correlation function } \\ G_{2}(\tau) & : \text { second order correlation function } \\ i & : \text { channel number } \\ j & : \text { channel number } \\ K & : \text { Boltzmann constant } \\ k & : \text { channel number } \\ l & : \text { channel number } \\ n & : \text { channel number } \\ n_{0} & : \text { solvent refractive index } \\ n(t) & : \text { count number of photon at time } t \\ n(t+\tau) & : \text { count number at time } t+\tau \\ q & : \text { absolute value of scattering vector } \\ q_{0} \% & : \text { frequency of histogram }\end{array}$

\section{Nomenclature}

$\begin{array}{rll}\left(\mathrm{m}^{2} / \mathrm{s}\right) & T & : \text { absolute temperature } \\ (\mathrm{m}) & T_{0} & : \text { fundamental sampling time } \\ (-) & T_{\mathrm{n}} & : \text { sampling time at } n \text { channel number } \\ (-) & u & : \text { ratio } \\ (-) & v & : \text { ratio } \\ (-) & x & : \text { variable } \\ (-) & \alpha & \text { : solution } \\ (\mathrm{J} / \mathrm{K}) & \beta & : \text { solution } \\ (-) & \Gamma & : \text { characteristic decay constant } \\ (-) & \eta_{0} & : \text { viscosity } \\ (-) & \theta & : \text { scattering angle } \\ (-) & \lambda_{0} & : \text { wavelength of light in vacuum } \\ (-) & \tau & : \text { delay time } \\ (-) & \langle> & : \text { ensemble average } \\ (-) & {[\text { ] }} & \text { : integer } \\ (\%) & & \end{array}$

$(-)$ $(-)$ $(\mathrm{mPa} \cdot \mathrm{s})$ (deg)

\section{References}

1) Berne, J. B. and R. Pecora: "Dynamic Light Scattering”, pp. 48-50, Dover Publications, Inc. N. Y. (2000)

2) Yamaguchi, T., Y. Azuma and K. Okuyama : "Development of Photon Correlation Spectroscopy Instrument for Size Analysis of Nanometer-Sized Particle of below 10nm”, J. Soc. Powder Technol., Japan, 42, No. 1, 11-16 (2005)

3) Yamaguchi, T. and K. Okuyama : "Development of PCS Apparatus for Polydisperse Single Nanoparticles and Its Performance Evaluation", J. Soc. Powder Technol., Japan, 44, No. 1, 19-27 (2007)
4 ) Ostrowsky, N., D. Sornette, P. Paker and E. R. Pike : "Exponential Sampling Method for Light Scattering Polydispersity Analysis”, Optica Acta, 28, 1059 (1981)

5 ) Schatzel, K., M. Drewel and S. Stimac: "Photon Correlation Measurements at Large Lag Times : Improving Stastical Accuracy", J. Modern Optics, 35, No.4, $711-718$ (1988)

6 ) Yamaguchi, T. and S. Kawarabayashi : "Bias Free Correlator with Real Time Sampling to Measure Particle Size”, Abst. $7^{\text {th }}$ Int. Conf. on OPC 2004, p. 84 (2004) 